\title{
Residual Stresses in Weld Overlay Tubes: A Finite Element Study
}

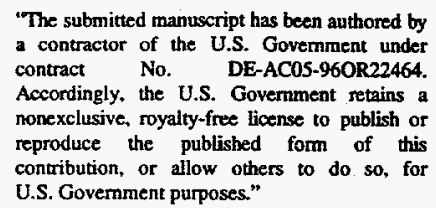

B. Taljat, T. Zacharia, X.-L. Wang, J. R. Keiser, Z. Feng ${ }^{\dagger}$, and M. J. Jirinec ${ }^{\dagger}$ Oak Ridge National Laboratory, Metals and Ceramics Division, Oak Ridge, TN 37831-6140, USA

$\dagger \quad$ Edison Welding Institute, 1100 Kinnear Road, Columbus, OH 43212, USA

$\ddagger \quad$ Welding Services, Inc., 2225 Skyland Ct., Norcross, GA 30071, USA

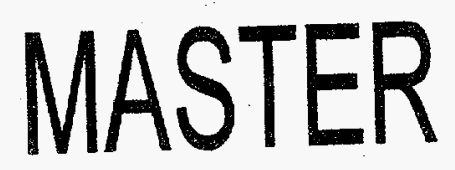

\begin{abstract}
Residual stresses and strains in a tube with circumferential weld overlay were analyzed by the finite element (FE) method. The objective of this work was to develop and verify a FE model, to determine the magnitude and distribution of residual stresses in the weld overlay tube, and to evaluate the significance of two contributing factors to residual stress: (1) difference in material properties between tube and weld material, and (2) thermal gradients in the weld.

An axisymmetric FE model was developed to simulate the circumferential two-layer welding process of alloy 625 overlay on SA210 tube. The first layer was modeled as a gas metal arc welding process with filler metal, whereas the autogenuous gas tungsten arc welding process was modeled for the second layer.

Neutron diffraction technique was used to experimentally determine residual elastic strains in the weld overlay tube. Comparison with the FE results shows overall good agreement. Both the experimental and FE results show high compressive stresses at the inside tube surface and high tensile stresses in the weld overlay. This suggests that weld overlay may be used to relieve tensile or produce compressive stresses at the inside tube surface, which is significant for applications where crack initiation is found at the root pass of the joining weld.
\end{abstract}

\section{INTRODUCTION}

Corrosion-resistant weld overlay, typically alloy 625 or type 309 stainless steel, on carbon steel tubes (SA210 Grade A1 carbon steel) is being considered as an alternative manufacturing process to coextrusion of composite tubes used for recovery furnaces in kraft pulp and paper mills.

The objective of this study was to analyze the residual stress state after the welding process; this evaluation is important for a successful study of the stress conditions during operation of a recovery boiler (Singbeil et al., 1996; Keiser et al., 1996). The in-service stresses are a crucial factor in that they can either assist or prevent the initiation and/or propagation of cracks under various mechanisms, such as stresscorrosion cracking, thermal fatigue, or a combination of these.

In general, the physics of a welding process is very complex. The welding arc produces temperatures which are close to the boiling temperature of the metal, instantaneously melting the material in its vicinity. The heat input is defined by welding parameters, which, combined with heat losses, are functions of the type of materials used, geometry and size of the workpiece, fixturing, etc., and determine the fusion zone size and the intensity of thermal gradients during cooling. The intensity of thermal gradients during cooling influences the deformation patterns, which finally produce the residual stress distribution in the product. Various types of welding processes have been successfully modeled by finite element analysis in order to determine welding residual stresses (Mahin et al., 1991; Roelens et al., 1996; and Jovanovic et al., 1986).

An axisymmetric finite element (FE) model was developed to simulate the weld overlay clading process performed in two layers [gas metal arc welding (GMAW) for the first layer and gas tungsten arc welding (GTAW) for the second layer]. Thermal and mechanical analyses were performed using ABAQUS FE code (ABAQUS, 1996). Part of this work included verification of the developed $\mathrm{FE}$ model. Neutron diffraction (ND) was then used to measure the residual elastic strains in an as-manufactured tube (Wang et al., 1996), and the results were used for comparison with the FE results. The comparison is very promising for future $\mathrm{FE}$ studies of residual stresses in weldments. Also, the effects of weld material and different welding procedures (e.g. heat input, cooling) on residual stresses were evaluated and are discussed in this paper.

\section{EXPERIMENTAL}

The weld overlay consists of two layers continuously applied in the circumferential direction, resulting in a spiral $\left(360^{\circ}\right)$ weld (see Fig. 1). The first layer is made with a single electrode (1 mm diameter approximately) by the automated GMAW process with filler material. The autogenuous GTAW process is used to make the second weld layer. The purpose of the second layer is to temper the heat affected zone. Weld step-over is approximately $9 \mathrm{~mm}$ which means that a special welding technique is used (electrode weaving) to achieve the desired weld width. The tube is water cooled during welding and preheat is not applied. Table 1 shows the welding parameters adequate for modeling. 
Table 1. Welding parameters.

\begin{tabular}{lcc}
\hline & Layer 1 & Layer 2 \\
\hline \hline Welding technique & GMAW & GTAW \\
Welding current [A] & $170-200$ & $360-400$ \\
Welding current [A]; Case C & $170-200$ & $200-250$ \\
Welding voltage [V] & $20-25$ & $9-12$ \\
Travel speed [mm/s] & $12-13$ & $12-13$ \\
Electrode diameter [mm] & 1.2 & 3.2 \\
Weave width [mm] & $9-12$ & $9-12$ \\
Step-over [mm] & $9-10$ & $9-10$ \\
Water flow rate [cm ${ }^{3} / \mathrm{s}$ ] & $946-1892$ & $946-1892$ \\
Preheat [ ['C]; Case C & 93.3 & 93.3 \\
\hline
\end{tabular}

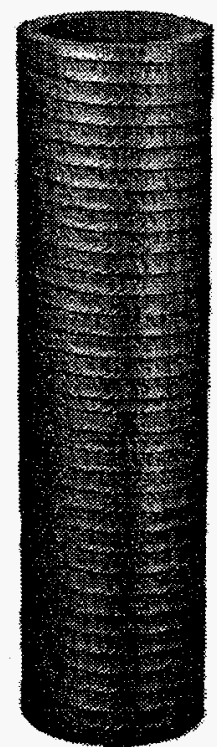

Fig. 1. Weld overlay tube

The neutron diffraction measurements were conducted separately in a parallel study. Details of the experiment have been reported elsewhere (Wang et al., 1996), so only an outline is given here. Basically, this method uses one or more diffraction peaks as a strain sensor. From the measured diffraction peak position, the interplanar lattice spacing is obtained. The lattice strain is then determined using the equation,

$$
\varepsilon=\frac{d-d_{0}}{d_{0}}
$$

where $d_{0}$ is the unstressed lattice spacing. In this study, $d_{0}$ for each material was obtained by measuring of a stress-free reference specimen, prepared using a part of the supplied weld overlay tube.

The incident and diffracted beams were defined, respectively, by a masking slit inserted before and after the specimen. The intersection of the incident and diffracted beams formed the sampling or gauge volume. Strain mapping was accomplished using a three-dimensional translation stage mounted on the sample table of the neutron diffractometer. All neutron diffraction measurements were performed at the High Flux Isotope Reactor of Oak Ridge National Laboratory.

Note that the slits used for radial and tangential strain measurements are $30 \mathrm{~mm}$ long and $4 \mathrm{~mm}$ long slits are used for axial strain measurements. This means that the measured strains in the radial and tangential directions represent average values across several weld passes. This is an important factor to keep in mind when the ND results are compared with FE calculations. Also, to ensure that the obtained strain values are representative. the radjal and hoop strain profiles were determined at several locations around the tube, and the results were averaged. The axial strain was measured at only one angular position. because of the smail sampling volume and hence long counting time required for this measurement geometry.

\section{FINITE ELEMENT ANALYSIS}

Three different cases were considered in order to address the effect of weld material and some weiding parameters on the residual stress field. Case A: Alloy 625 weld on SA210 carbon steel tube with welding parameters specified in Table 1. water cooling, and no preheat (same as experimental tube): Cuse B: SA210 carbon steel weld on a tube of the same material, other parameters are the same as for Case $A$; Case $\mathrm{C}$ : same as Case A, but different welding amperage, preheat, and no water cooling (see Table 1).

An axisymmetric model was considered because of the circumferential welding direction. This assumption considerably simplifies the modeling effor and reduces the computational time. but requires acceptance of additional assumptions, which mainly address how heat is introduced into the model.

The overall length of the tube considered in the model is $500 \mathrm{~mm}$. which is approximately 9 tumes the length of the weld overlay considered in the analysis. The reason for selecting this tube length is to appropriately model the conductive, convective, and radiative heat transfer during welding. Changing the tube length affects the intensity of the thermal sink (cooling water) and thus the steady state temperature of the tube during welding. The model length was therefore selected on the basis of the calculated temperanure not exceeding $40^{\circ} \mathrm{C}$ at a particular distant point on the tube (Cases $\mathrm{A}$ and B). Figure 2 shows the finite element model, essential dimensions, and some mesh details. In addition. Fig. 2 shows the sections at which the residual stress and strain results are presented.
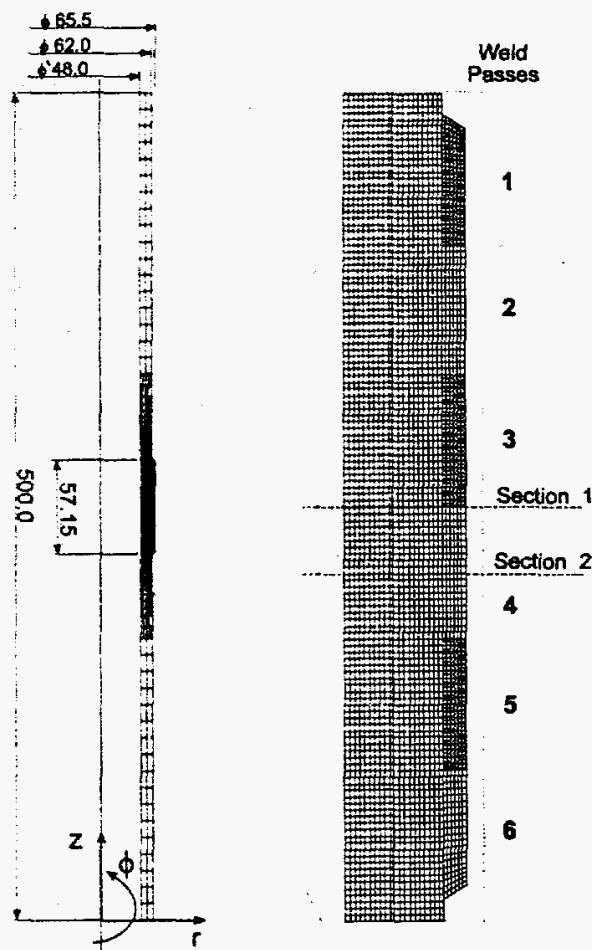

Fig. 2. FE model (dimensions are in $\mathrm{mm}$ ). 


\section{DISCLAIMER}

This report was prepared as an account of work sponsored by an agency of the United States Government. Neither the United States Government nor any agency thereof, nor any of their employees, make any warranty, express or implied, or assumes any legal liability or responsibility for the accuracy, completeness, or usefulness of any information, apparatus, product, or process disclosed, or represents that its use would not infringe privately owned rights. Reference herein to any specific commercial product, process, or service by trade name, trademark, manufacturer, or otherwise does not necessarily constitute or imply its endorsement, recommendation, or favoring by the United States Government or any agency thereof. The views and opinions of authors expressed herein do not necessarily state or reflect those of the United States Government or any agency thereof. 


\section{DISCLAIMER}

Portions of this document may be illegible in electronic image products. Images are produced from the best available original document. 
The core of the modeling effort is in the user subroutines for ABAQUS code, which allow the simulation of the welding arc movement over the material. Thermal and mechanical analyses are uncoupled and performed in two separate runs. First, the thermal analysis is performed calculating the transient temperature distributions during welding. The model for the mechanical analysis is similar to the thermal one, except for the type of finite elements and the applied boundary conditions. The mechanical part relies on the thermal analysis results and calculates the stress-strain distribution on the basis of the temperature gradients.

\section{Thermal Analysis}

Several assumptions and simplifications were made in the thermal model. The welding arc was modeled by a heat flux moving across the observed section of the tube. Electrode weaving was not modeled, instead, a wider heat flux was assumed, which corresponds to the actual step over width. To account for heat transfer effects due to the fluid flow in the weld pool, an increase in the thermal conductivity above the melting temperature was assumed. The phase transformation effect was modeled by specifying the latent heat of fusion. To account for heat losses, the radiative and convective heat transfer at the weld surface and the convective heat transfer to the cooling water and the surrounding air were modeled.

The overall heat flux was calculated as:

$$
\Phi=\eta E I
$$

where $\eta$ represents the efficiency factor, which accounts for radiative and other losses from the arc to the ambient environment, $E$ is voltage, and $I$ electric current. The heat flux distribution in the material is defined by the equation:

$$
f(r, \phi, z)=f_{I} e^{-3\left[\left(\frac{r}{a}\right)^{2}+\left(\frac{\phi}{b}\right)^{2}+\left(\frac{z}{c}\right)^{2}\right]}
$$

where $r, \phi, z$ are the radial, tangential, and axial coordinates respectively, with the origin at the material surface. Constants $2 a, 2 b$, and $2 c$ represent the characteristic arc dimensions in $r, \phi$, and $z$ direction within which $95 \%$ of the energy is transferred. The constant $f_{I}$ can be derived by integrating the function $f(r, \phi, z)$ in the material half space beneath the welding arc $(-\infty<r<0,-\infty<\phi<\infty,-\infty<z<\infty)$ :

$$
f_{I}=\eta E I \frac{I}{a b c} \frac{6 \sqrt{3}}{\pi \sqrt{\pi}}
$$

Since the axisymmetric model was assumed, the dimension $b$ does not exist. Therefore, the tangential dimension was simulated by adding the time component to the model:

$$
\left(\frac{\phi}{b}\right)^{2}=\left[\left(\frac{v}{b t}\right)-\frac{t_{t}}{2}\right]^{2}
$$

where $t$ is the current time and $t_{t}$ is the total time the electrode needs to travel over the observed point, taking into account the actual welding speed, $v$ (see Table 1). Equation 3 combined with Eq. 5 models the volumetric Gaussian distribution of heat flux by transferring the nonexistent $\phi$ dimension of the axisymmetric model into the time dimension.

Three computational steps are required to complete one welding pass. In the first step the heat source passes across the observed section and heats/melts the tube material. The filler material is added in the second step. The third step is required because of the axisymmetric model assumption and simulates the cooling of the observed section before the electrode returns for the next welding pass. The cooling time equals the time the electrode travels around the tube with the actual welding speed. Because of the axisymmetric model assumption the heat is simultancously applied and the material is simultaneously melted and deposited around the circumference. The cooling in the third step undergoes the ame assumption which creates sharp thermal cycies. To assure more gradual heat distribution. which can better represent the conunuous or progressive heat input in the circumierential direction in actual welding, additional heat is applied during the third step. The distributed heat flux, which equals the welding heat flux. is applied to the weld section of the tube during the cooling time. Six welding passes are simulated in order to obtain a weld of sufficient length and to get an uniform region of residual stresses not affected by the start and end effect of the welding process. After the first layer is finished, the tube is cooled to room temperature and then the second weld layer is started. The computational assumptions for the second layer are similar. Each welding pass for the second layer consists only of two computational steps (heating and cooling), because there is no filler material to be added. After the last (sixth) pass of the second layer the tube is again cooled to room temperature.

\section{Mechanical Analysis}

An elasto-plastic constitutive law was used in the mechanical analysis. The temperature dependent mechanical properties were obtained elsewhere (Swindeman. 1996; Boyer et al., 1992; Rothman, 1989: and Smith. 1970). Both yield and ultimate stresses were reduced to $10 \mathrm{MPa}$ at the melting temperature to simulate the low strength at high temperatures. Elastic modulus was also given as a function of temperature and reduced to a small value (500 MPa) at high temperatures. Phase transformation effects due to rapid cooling on mechanical properties of carbon steel were not included in the analysis.

The same FE mesh as in the thermal analysis was used. The analysis is based on the temperature gradients calculated in the thermal analysis which represent the input information or loading. The tube was not restrained during mechanical analysis, since it is rotating and simultaneously moving in the axial direction during the actual welding process.

Residual stresses and elastic strains were calculated after the welding process was completed and the tube had cooled to room temperature. Residual elastic strains were evaluated for comparison with the ND results. The purpose of the comparison is to validate the finite element model (sce Fig. 3 ).

\section{RESULTS AND DISCLSSION}

\section{Verification of the FE model}

The analysis was verified by comparing the calculated elastic strains of Case A to those measured by ND technique. Since elastic strains are directly measured by ND, their comparison to FE elastic strains avoids the error from conversion to stress values (Mahin et al., 1991). Residual elastic strains were measured in three directions (radial. axial, and tangential), and these were used to determine the accuracy of the FE model. Figure 3 shows the comparison. Note that the presented FE results were averaged between the two throughthickness sections where the highest stress variation occurred (section 1: between the two weld passes, and section 2: center of the weld pass; see Fig. 2). Also note that the ND results were measured 
across several weld passes (radial and tangential components), and therefore, represent an average strain.
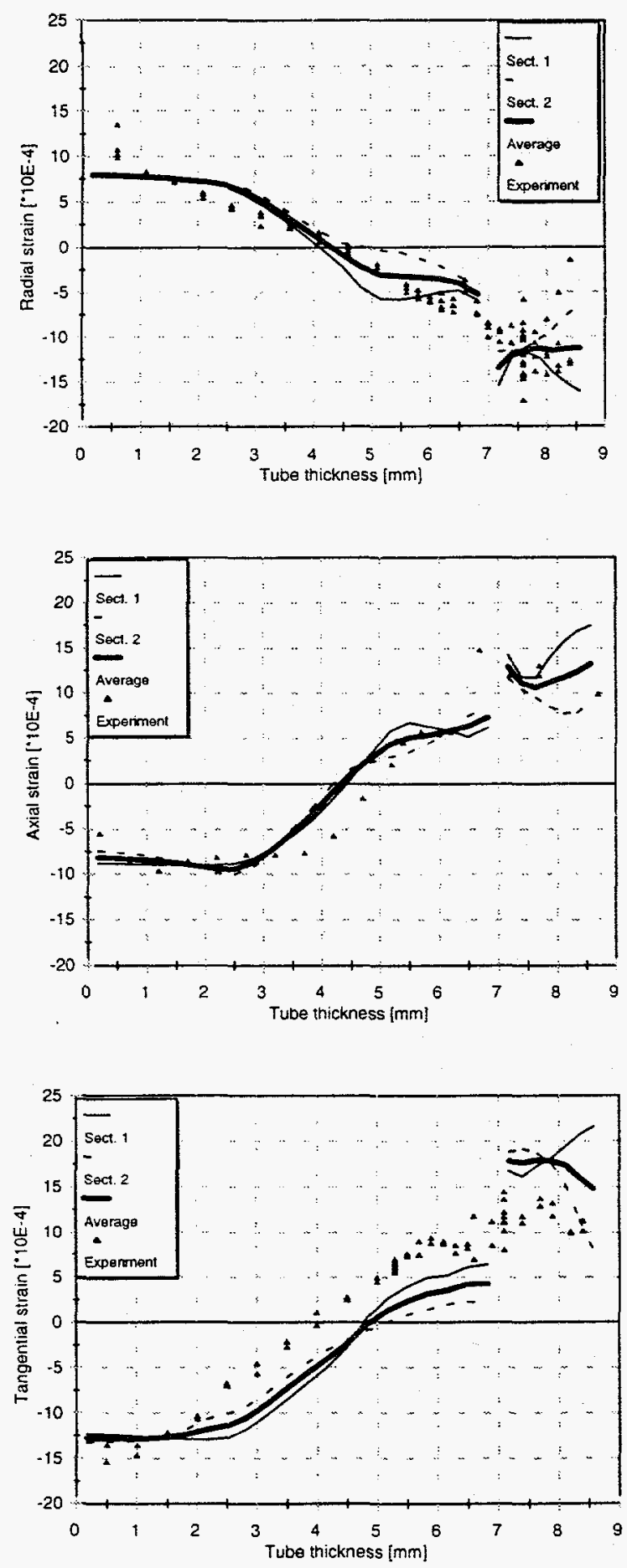

Fig. 3. Comparison of elastic strain components (radial, axial, tangential) measured by ND and calculated by finite element method. Note that the original thickness of the carbon steel tube is $7 \mathrm{~mm}$.

Based on the results presented in Fig. 3, it can be concluded that the agreement in axial and radial directions is excellent. The calculated and measured tangential strains at the inner tube surface agree well. In other areas, however, the calculated tangential strains are consistently higher. This may be explained by the macroscopic model nature, which prevents capture of the micro effects at the interface between the two materials during deposition, solidification, and cooling transients. However, the overestimation in tangential component could also be explained as follows. The axisymmetric model assumption means that the material deposition around the circumference is made simultaneously. Because the circular layer of material is at high temperature during deposition on the tube, which is at room temperature, considerable shrinkage of the deposited layer occurs when the composite is cooled to room temperature. This creates tensile stresses in the overlay and compressive stresses in the base material. The physics of gradual deposition in the circumferential direction may have different effects on shrinkage as the deposited material cools while the welding is still in progress. Intuition suggests that the tangential shrinkage may not be as intense in the case of continuous progressive solidification and cooling in the circumferential direction (actual welding process) compared to the simultaneous weld solidification and cooling of the entire circumference (axisymmetric model). This might contribute to the higher stress magnitude in tangential direction.

\section{Residual stresses}

Residual stresses and strains were evaluated after the welding process was completed and the tube had cooled to room temperature. The calculated stresses along the two section lines were averaged and are presented in Figs. 4-6. The two middle passes were evaluated to minimize the start and end weld effects on the stress distribution. Comparison of the calculated residual stresses for the three analyzed cases are presented in Fig: 4 for radial, Fig. 5 for axial, and Fig. 6 for tangential direction. Shaded axial crossection plots for the SA210/Alloy 625 tube (Case A) are presented in Fig. 7 to show the stress pattern in the cross-section.

Averaged radial stresses are compressive and their magnitude is not significant (up to $50 \mathrm{MPa}$ for Cases A and B; up to $100 \mathrm{MPa}$ for Case C; see Fig. 4). The stress pattern is unique in that the stresses underneath each weld pass are tensile, whereas they are compressive underneath the interface between the two weld passes (see shaded piot of Fig. 7).

Axial residual stresses in the alloy 625 weld overlay are tensile and lower than the yield stress (the calculated average stress is between 350 and $400 \mathrm{MPa}$ ). Stresses in the carbon steel are tensile at the interface (200 $\mathrm{MPa})$, decrease to about a $300 \mathrm{MPa}$ compressive stress at approximately one third of the tube thickness, and remain constant to the inner surface (see Fig. 5). Stresses in the carbon steel overlay (Case B) are considerably lower, with the maximum of $200 \mathrm{MPa}$ at the outside surface. Stresses at the inner surface are also compressive and lower than in Case A (around $200 \mathrm{MPa}$ ). The results of Case $\mathrm{C}$ show that preheat, removal of water cooling, and smaller heat input for the second weld layer significantly reduce the axial stresses in the weld overlay tube. The axial stress is approximately $100 \mathrm{MPa}$ lower in the overlay, as well as in the carbon steel core.

The calculated tangential residual stress distribution is similar (see Fig. 6). Stresses in the overlay and in the carbon steel core are higher by about $100 \mathrm{MPa}$ compared to the axial stress. Stresses in the carbon steel overlay are tensile with a magnitude between 100 and $200 \mathrm{MPa}$, whereas they are higher in compression at the inner surface ( $350 \mathrm{MPa}$ ). The difference in heat input also significantly reduces the tangential stresses throughout the tube thickness. According to the explanation given in the previous section, the tangential stresses are expected to overestimate the actual value. 


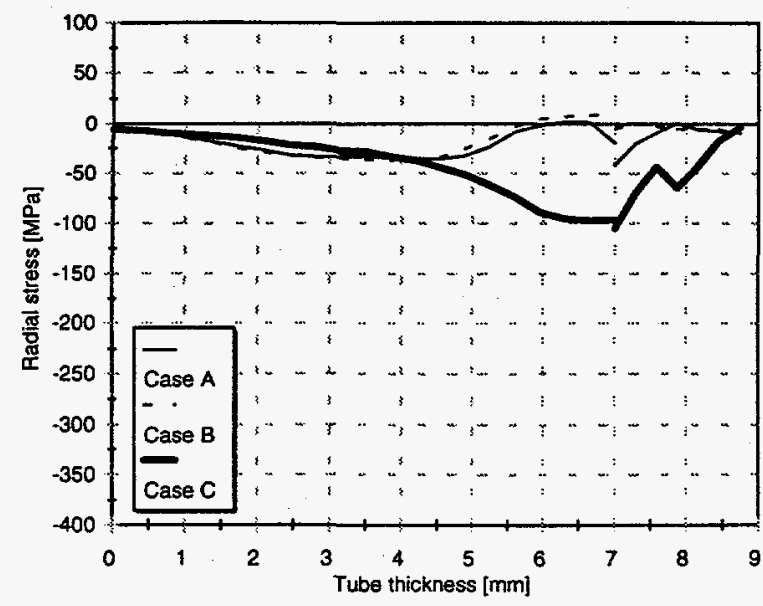

Fig. 4. Radial residual stress for the three analyzed cases.

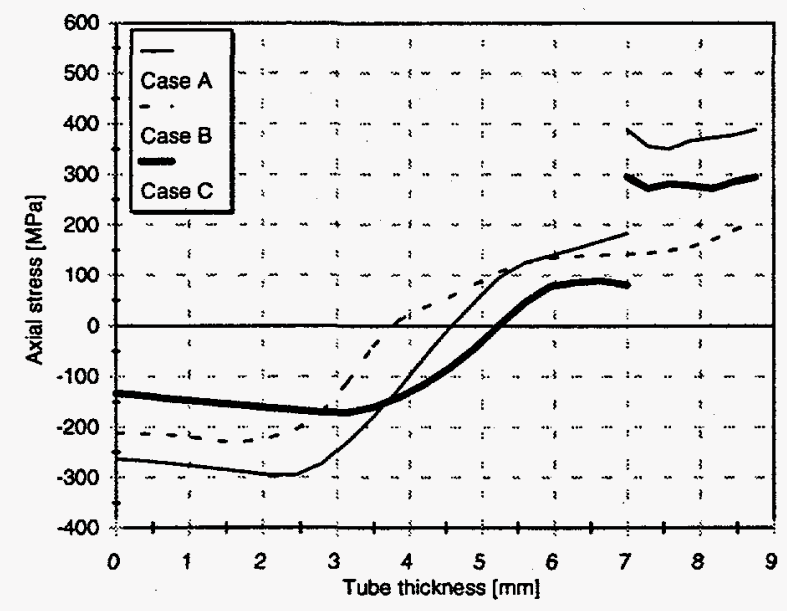

Fig. 5. Axial residual stress for the three analyzed cases.

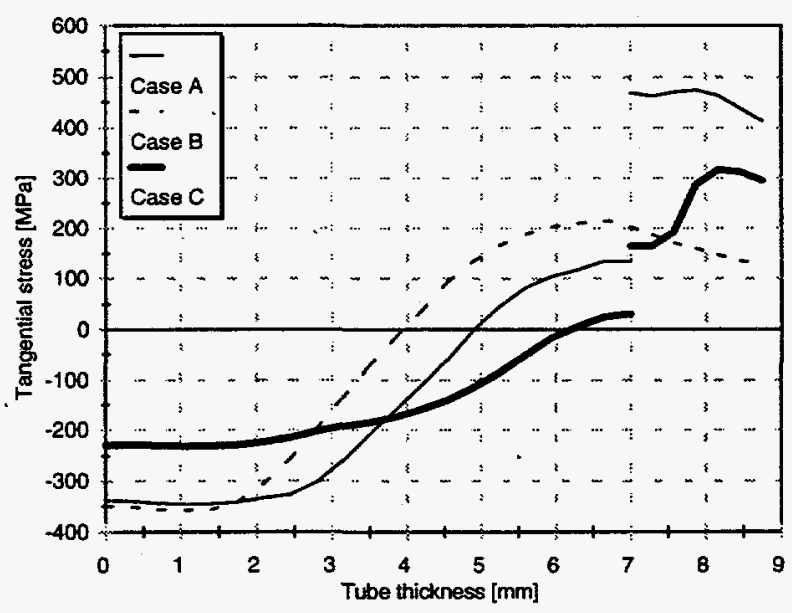

Fig. 6. Tangential residual stress for the three analyzed cases.

The FE results also show that the whole tube was plastically deformed during the welding process. The highest plastic strain occurred at the interface (up to 0.18 ). It is lower at the inner tube surface (about 0.02 ), but higher in the weld overlay (around 0.08 ).
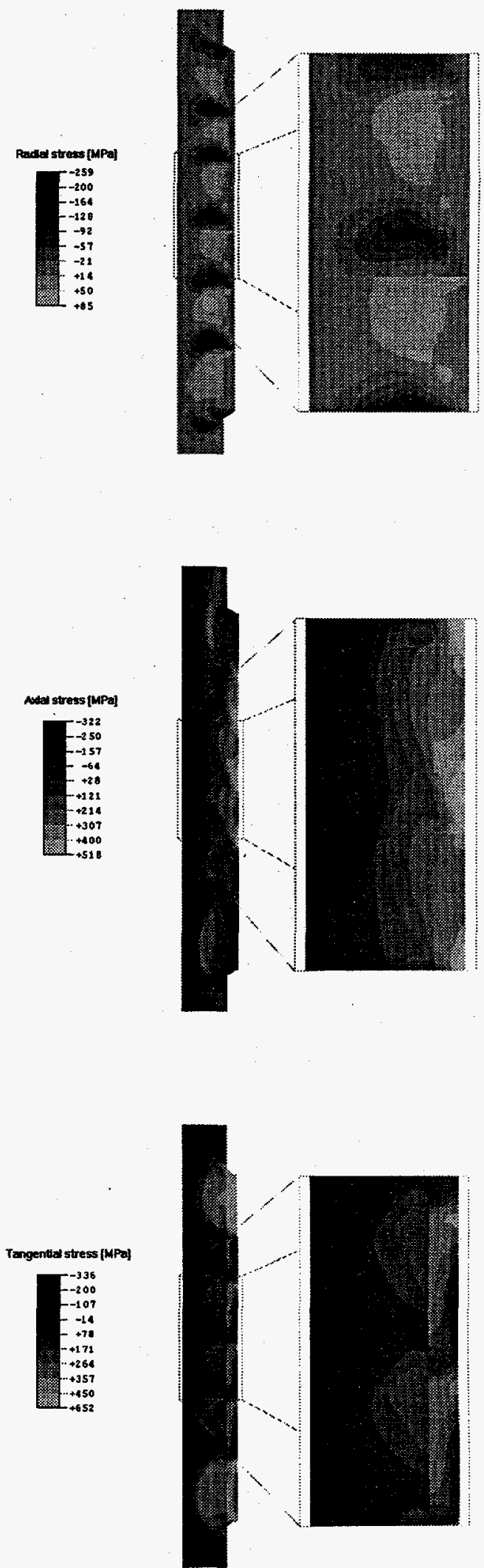

Fig. 7. Residual stress distribution in SA210/Alloy625 tube (Case A). 
In general, residual stresses in the weld overlay and at the interface of the two materials are high and tensile, which is important information for evaluating the weld overlay tube with respect to potential failure mechanisms.

The carbon steel weld overlay produces high compressive stresses at the inner surface, which may be an important consideration in applications where it is beneficial to relieve tensile stresses at the tube inner surface.

\section{CONCLUSIONS}

In this study, an axisymmetric finite element model was developed for the simulation of the spiral weld overlay process. The residual stress and strain distributions in the weld overlay tube were analyzed. The residual elastic strain distribution was measured using the neutron diffraction technique in a parallel study (Wang et al., 1996). The measured data were used to verify the developed FE model. Excellent agreement in radial and axial elastic strain components was obtained, while the calculated tangential strains overestimated the measured values. The disagreement in the tangential component, which may be due to the simplification of the welding process with an axisymmetric model, is discussed in this paper.

The calculated axial stresses in the weld overlay are very high and are tensile. They are compressive and of lower magnitude at the inner tube surface. The calculated tangential stresses in the overlay are tensile and almost reach the yield stress. The comparison of measured and calculated elastic strains suggests that the calculated tangential stress component, especially in the weld overlay, is higher than the actual stress. Radial stresses are mainly compressive and their magnitude is not significant compared to the axial and tangential stress components.

The analysis shows that the whole section (tube and weld) undergoes plastic deformation during welding. The plastic strain is the highest at the interface and in the weld overlay.

Residual stresses due to a carbon steel weld are similarly distributed, but of lower magnitude. This shows that such welds can be used in applications where one wants to relieve tensile or produce compressive stresses at the inner tube surface.

The FE results also show that different heat input and welding conditions (preheat, cooling, welding heat input) significantly affect the residual stress field. Applicaton of preheat, removal of water cooling, and lowering of welding heat input considerably reduced the axial and tangential stresses throughout the tube thickness.

\section{ACKNOWLEDGMENTS}

The authors would like to thank Drs. G. Sarma and R. W. Swindeman for reviewing the paper. The research was sponsored in part by an appointment to the Oak Ridge National Laboratory Postdoctoral Research Associates Program administered jointly by the Oak Ridge Institute for Science and Education and Oak Ridge National
Laboratory. The research was also sponsored by the U.S. Department of Energy, Assistant Secretary for Energy Efficiency and Renewable Energy, Office of Industrial Technologies, Advanced Industrial Materials Program, under contract DE-AC05-960R22464 with Lockheed Martin Energy Research Corp., and by the U.S. Navy, Office of Naval Research under interagency agreement DOE No. 1866-E126A1, Navy No. N000014-92-F-0063 under U.S. Department of Energy contract DE-AC05-960R22464 with Lockheed Martin Energy Research Corp.

\section{REFERENCES}

ABAQUS, 1996, “Users' Manual.” Version 5.5. Hibbitt, Karlson \& Sorensen.

Boyer, H. E., and Gall. T. L.. 1992. Editors. "Metals Handbook," Desk Edition, ASM Metals Park. OH.

Jovanovic, A., and Lucia, A. C.. 1986, "Analysis of Cladding Residual Stresses and Their Influence on the Structural Reliability of LWR Pressure Vessels," Int.J.Press. Ves.\&Piping pp 111-145, Vol 22.

Keiser, J. R., Taljat, B., Wang. X.-L., Maziasz, P. J., Hubbard, C. R. Swindeman. R. W., Singbeil. D. L., and Prescott, R., 1996, "Analysis of Composite Tube Cracking in Recovery Boiler Composite Floors," Proceedings of 1996 TAPPI Engineering Conference, pp693-705.

Mahin, K. W.. Winters. W.. Holden, T. M., Hosbons, R. R., and MacEwen. S. R.. 1991. "Prediction and Measurement of Residual Elastic Strain Distributions in Gas Tungsten Arc Welds," Welding Research Supplement, pp245 - 254

Roelens, J. B., 1996, "Numerical Simulation of Some Multipass Submerged Arc Welding Determination of the Residual Stresses and Comparison With Experimental Measurements," The Eight International Conference on Pressure Vessel Technology, Montreal, Canada.

Rothman. M. F., 1989, Consulting Editor, "High Temperature Property Data: Ferrous Alloys," ASM Intermational, Metals Park, OH.

Singbeil, D. L., Prescott. R., Keiser, J. R., and Swindeman, R. W., 1996, "Composite Tube Cracking in Kraft Recovery Boilers," Draft technical report. Pulp and Paper Institute of Canada.

Smith, G. V., 1970, "An Evaluation of the Elevated Temperature Tensile and Creep-Rupture Properties of Wrought Carbon Steel. “ ASTM, Philadelphia.

Swindeman. R. W., 1996. "A Review of Thermal/Mechanical Fatigue in Composite Tube Materials." Draft technical report, Oak Ridge National Laboratory.

Wang, X.-L., Payzant, E. A., Taljat, B.. Hubbard, C. R., Keiser, J. R., and Jirinec, M. J., 1996. "Experimental Determination of the Residual Stresses in a Spiral Weld Overlay Tube," submitted to Mat. Sci. Eng. 